\title{
Temática circense en los cuentos El vuelo de los cóndores de Abraham Valdelomar y Fénix de Julio Ramón Ribeyro
}

\section{The circus theme in the short stories El vuelo de los cóndores by Abraham Valdelomar and Fénix by Julio Ramón Ribeyro}

Jesús Humberto Santivañez Valle Universidad Nacional del Centro del Perú, Huancayo, Perú santillo5@hotmail.com

Resumen: Este trabajo examina el tema del circo en dos importantes cuentos de la literatura peruana, El vuelo de los cóndores y Fénix, narraciones que pertenecen al Postmodernismo y al Neorrealismo respectivamente. Mediante una metodología de crítica sociológica aplicada a la literatura, se analizarán tres tópicos en común en el contenido de estos dos cuentos clásicos de la literatura peruana, los cuales son: la problemática laboral del circo, principales personajes circenses y el valor social del circo. Los resultados de este análisis servirán para comprender la temática circense en la obra de ambos escritores, Abraham Valdelomar y Julio Ramón Ribeyro.

Palabras clave: cuento peruano, postmodernismo peruano, neorrealismo peruano, crítica literaria, circo. 
Abstract: This research examines the theme of the circus in two important short stories of Peruviam literature, El vuelo de los cóndores and Fénix, which belong to Postmodernism and Neorealism respectively. Through the sociological critique methodology in the literature, three topics in common will be analysed, such as the circus's labor problems, main circus characters and the social value of the circus in these two classic tales of Peruvian literature. The results of this analysis will help us understand the circus theme in the work of both writers, Abraham Valdelomar and Julio Ramón Ribeyro.

Keywords: Peruvian Short Story, Peruvian Postmodernism, Peruvian Neorealism, Literary Criticism, Circus.

Recibido: I9 de febrero de 2020

Aceptado: Io de mayo de 2020 https://dx.doi.org/I O.I 5 I 74/rv.vi 3i27.532

Se entiende al circo como un lugar atractivo al ser humano y, lización de su expresión conviven toda una amalgama de formas estéticas como la danza, la música, el teatro, la pintura, entre otras. En cuanto a la literatura, esta no deja de participar en el fenómeno circense, tomándolo en cuenta desde diversas formas en su abordaje.

Desde una perspectiva dialéctica, el circo tiene un carácter complejo en donde confluyen, se relacionan y se diferencian toda una amalgama de estratos sociales unidos por el espectáculo: "El circo es entonces un arte aristocrático y popular a la vez. Hace compatibles dos nociones que, en general, se excluyen. Al momento de su creación, a finales del siglo XVIII, el circo moderno atrae un público de aristócratas y burgueses, pero con el paso de los siglos siguientes 
y de su difusión geográfica, se abrirá a un abanico muy amplio de categorías sociales" (Bailly, 2009: 64).

Por esta razón, entendemos que los escritores peruanos, Abraham Valdelomar y Julio Ramón Ribeyro, como artistas sensibles ante las circunstancias históricas y sociales en que se desarrollaron, manifestaron atracción hacia el fenómeno circense y exteriorizaron dicho interés mediante la creación de los cuentos El vuelo de los cóndores y Fénix, respectivamente; narraciones concebidas en diferentes contextos históricos, pero que se vinculan por el común denominador del circo como principal escenario literario.

En primer lugar, El vuelo de los cóndores fue publicado en 1918 como parte del libro El caballero Carmelo. Este "cuento criollo" es un hito en la narrativa peruana, ya que marca el inicio del Postmodernismo, puesto que las acciones se llevan a cabo en el apacible puerto de Pisco, utilizando un lenguaje sencillo que, en su acertada estética, abandona el exotismo inicial del Modernismo para volcarse a temas más cercanos e íntimos en las costumbres criollas al interior de la sociedad peruana (Garayar, 2014: 25).

Fénix, por su lado, fue publicado en 1964 como parte del libro Tres historias sublevantes. Sus acciones se ambientan en la selva peruana y va dedicado a la memoria del poeta revolucionario Javier Heraud. A su autor, Julio Ramón Ribeyro, se le ha catalogado como "neorrealista", ya que formó parte de la Generación del 50. Los narradores de esta generación, influenciados por una tradición literaria vanguardista, renuevan las letras peruanas, debido a que modernizaron el discurso narrativo al poner en práctica diversas técnicas literarias de tradición universal en la escena local, como las utilizadas en el Siglo de Oro Español, la narrativa decimonónica, la cuentística misteriosa de Poe, el expresionismo de Kafka, el monólogo interior de Joyce o la literatura de vanguardia de la Generación Perdida (Tenorio, 2002: 124). 
Como se aprecia, las circunstancias de Valdelomar y Ribeyro son distintas. La distancia cronológica entre la publicación de los dos cuentos es de 46 años. Además, al nacimiento de Ribeyro, 1929, Valdelomar llevaba muerto una década. Es innegable que durante estos ańos hubo muchos cambios significativos en las estructuras de la sociedad peruana. Por ello, también existe una gran diferencia estética en la cuentística de ambos autores. Entendemos que cada hombre es producto de su tiempo y, en este caso, se refleja en la producción de su obra artística. Es por esta razón que mediante la crítica sociológica aplicada a la literatura buscaremos profundizar en El vuelo de los cóndores y Fénix.

Partimos entendiendo que el contenido de la literatura encierra descripciones de la realidad social que le es contemporánea. Más aún, la literatura no solamente es un documento para la sociología, sino que se convierte en sociología propiamente tal, en la medida en que es reflexión sobre la sociedad, sobre la situación que le rodea al hombre en la sociedad, o sobre su propia condición en la sociedad (Lukács, 1989: 89).

Así, desde esta base realista de la literatura y el reflejo estético que esta ejerce con respecto al individuo decodificador del mensaje literario, la acción de crítica hacia el objeto estético que desarrollaremos en el presente trabajo, tratará de ser sensiblemente objetiva, en la medida que la crítica estética puede serlo, teniendo como variable al hombre y su complejidad, como lo sostuvo de manera paradigmática el maestro José Carlos Mariátegui cuando abordó la crítica literaria peruana en su ya célebre séptimo ensayo: "Pero esto no quiere decir que considere el fenómeno literario o artístico desde puntos de vista extraestéticos, sino que mi concepción se unimisma, en la intimidad de mi conciencia, con mis concepciones morales, políticas y religiosas, y que, sin dejar de ser concepción estrictamente estética, no puede operar independiente o diversamente" (Mariátegui, 2010: 181). 
Por lo tanto, siguiendo la anterior directriz en sus bondades y limitaciones, ejerceremos la función de crítica literaria, tomando en cuenta el común denominador del circo como microcosmos que refleja a una determinada sociedad. Es por ello que el presente estudio literario busca comprender la temática circense en ambas narraciones y, guiados por tal objetivo, analiza tres aspectos en concreto, los cuales son: a) la problemática del circo como negocio de explotación laboral, b) principales personajes que integran el circo y, c) valor social que cumple el circo en estas dos piezas de la cuentística peruana.

\section{Problemática del circo como negocio de explotación laboral}

El circo es una entidad de actividad económica que involucra capital monetario y humano, conformado este último por los trabajadores. La literatura como arte no tiene como fin profundizar en dicho fenómeno, de esta labor se encargan las ciencias administrativas y económicas; sin embargo, la literatura representa diferentes aspectos que involucran al hombre en un mundo en plena ebullición mercantil.

Los dos cuentos que analizamos giran en torno al trabajo en el circo. El vuelo de los cóndores se divide en siete bloques numerados en romanos, desde la llegada del circo al puerto de Pisco hasta su retirada vía marítima, alcanzando su punto cumbre en el capítulo $\mathrm{V}$, pues se asiste al accidente que sufre la nińa acróbata, Miss Orquídea, al realizar de manera fallida la repetición de "El vuelo de los cóndores", un salto mortal en columpio, elevada a una altura de considerable envergadura.

Todo lo apreciamos desde la perspectiva del niño Abraham, quien se siente muy entusiasmado ante el arribo del circo a su pueblo. Él no conoce a detalle el engranaje productivo ni las dinámicas 
económicas que rigen la existencia de esta empresa de entretenimiento. Su impresión cambia al final del capítulo V: "Papá nos hizo salir, cruzamos las calles, tomamos el cochecito, y yo, mudo y triste, oyendo los comentarios, no sé qué cosas pensaba contra esa gente. Por primera vez comprendí entonces que había hombres muy malos" (Valdelomar, 2014: 147).

En este punto, su admiración infantil por el circo muda hacia una compasión melancólica que despierta un pensamiento crítico: ¿se sabe a qué hombres va dirigido el superlativo de "muy malos"? Existen dos posibilidades: el personal que integra el circo o el público espectador. $\mathrm{Al}$ parecer el calificativo recae en la gente del circo, ya que no se evidencia un tono autocrítico, puesto que el mismo niño Abraham y su familia integran al grueso del público; entonces, ¿qué gente del circo es la culpable? Pueda que el hombre viejo y grave que siempre acompaña a Miss Orquídea y quien maquina la repetición de la acrobacia trágica, ¿quizá sea este el dueño del circo? También pueda que el calificativo recaiga en sus acompańantes, de quienes se infiere que son sus padres, Miss Blutner y Mister Kendall. No lo sabremos con exactitud, pues la gramática del cuento se presta a una polivalencia semántica de obra abierta; lo innegable es que Miss Orquídea es víctima del espectáculo, siendo ella el eslabón más débil (infante, mujer y proletaria) por donde se puede quebrar la cadena mercantil del negocio y espectáculo circense.

En el siguiente bloque narrativo se asiste al desfile del circo, pero ya sin Miss Orquídea. Se aprecia el paseo de su caballo, con un listón negro, sin ella a cuestas. En el último bloque el niño Abraham reconoce a la nińa tullida sentada en una terraza cercana al mar, y de esta manera comienza el desarrollo de una inocente amistad. Asistimos al primer enamoramiento que experimenta el protagonista, sentimiento que va acompañado de compasión. En este apartado, el atractivo que ella despierta en el nińo llega a su 
esplendor cuando se miran en silencio en conexión emocional: "Yo me acercaba a la baranda de la terraza, pero no hablábamos. Siempre nos sonreíamos mudos y yo estaba mucho tiempo a su lado" (Valdelomar, 2014: 148). Experiencia que llega a su conclusión con la despedida que se dan ambos con la vocalización de un triste "adiós" la primera y la última vez en la que los dos se dirigen la palabra.

Recordemos que uno de los logros de Valdelomar es el haber sido pionero de la presencia del niño en la literatura peruana: "Demostramos que los cuentos anotados [El caballero Carmelo, El vuelo de los cóndores y El hipocampo de oro] dada su valía, antigüedad e influencia, se constituyen por sí mismos en precursores o iniciadores de la cuentística infanto-juvenil del Perú" (Vásquez, 2000: 134). Así, en este cuento los dos protagonistas son infantes: Abraham y Miss Orquídea. La voz que nos llega como ente narrador proviene del primero, y nosotros como lectores sufrimos con la suerte de la pequeña acróbata vía este testimonio emocional.

Uno se preguntará, ¿y qué tiene que ver esto con el negocio del circo? Pues bien, el circo es metáfora de la vida. "Al igual que en la poesía o en el arte, el circo se expresa con metáforas. Substituye imágenes y movimientos por objetos o cosas que pueden ser afectos (sensaciones, sentimientos), ideas, eventos, situaciones" (Bailly, 2009: 74), y en la vida existe injusticia, muchas de carácter laboral económico. El protagonista, a su temprana edad, puede juzgar de manera consciente sobre lo doloroso de este acontecer. Este hecho desagradable marca su primer amor. El niño Abraham fantaseará con la sutileza de la primera ilusión, pero también sufrirá al no poder hacer nada al respecto.

Si concebimos la categoría del trabajo desde una perspectiva marxista, como "una síntesis de acciones y/o actividades que, con esfuerzo y disciplina, violenta la realidad con el objetivo de la producción de potenciales valores de uso" (León, 2002: 76), encon- 
tramos que el trabajo que ejecuta Miss Orquídea no cumple con un objetivo humanístico, puesto que no la "enriquece mediante la sublimación de sus energías" (78), esto es, que al ser ejecutado el trabajo, ella no se realiza como humano íntegro. Veamos.

$\mathrm{Al}$ establecer diferencias entre los dos protagonistas, encontramos datos objetivos que demuestran que el ambiente en que vive Abraham es protector. Asistimos al amparo de sus padres tanto a nivel físico como psicológico; él solo tiene la obligación de ir a la escuela y portarse bien. Además, se observa la unión fraternal del protagonista con sus hermanos. En cambio, Miss Orquídea es una niña que trabaja en un ambiente peligroso; su realidad es completamente diferente a la de Abraham. Como se coligió anteriormente, labora junto a sus padres (lo más seguro es que proviene de una familia tradicional de acróbatas); sin embargo, ellos no la protegen adecuadamente, y este descuido tiene un resultado devastador. Ella no es libre, sino que sufre la dictadura laboral, antihumana, de los que administran el circo.

Ahora, analicemos el hecho de que la niña ya cumplió de manera eficaz la acrobacia mortal, pero a insistencia del negocio del espectáculo tiene que repetirlo, acción que ocasiona la tragedia. Reflexionemos sobre las consecuencias físicas inmediatas que son muy descarnadas en la literalidad del cuento: "El golpe fue sordo. La recogieron, escupió, y vi mancharse de sangre su pañuelo, perdida en brazos de esos hombres" (Valdelomar, 2014: 147). Se entiende que el daño físico que sufre es de consideración, a tal punto que origina una gran hemorragia, lo que la deja muy débil, deteriorada: "Vi una niña muy pálida, muy delgada, sentada, mirando desde allí el mar. No me equivocaba: era Miss Orquídea, en un gran sillón de brazos, envuelta en una manta verde, inmóvil" (148). Cuando Abraham se despide de ella, la impresión en el niño se relaciona con la palidez de enfermedad, con un caminar lento 
sin energías y con episodios repetitivos de tos (148), que evidencian las consecuencias del accidente acrobático.

Un objetivo de este cuento es presentar el recuerdo melancólico del primer amor. Desde una perspectiva infantil, se puede apreciar cómo la atracción maravillada por el esplendor del espectáculo se torna en tristeza trágica que raya con la muerte. Al analizar este hecho, nos damos cuenta de que la naturaleza mercantil del circo es la que origina lo trágico. La naturaleza explotadora de este negocio afectará al más débil: Miss Orquídea. Ella es una niña indefensa que arriesga su vida por el espectáculo. Aquí es importante reflexionar sobre la explotación laboral que sufre Miss Orquídea; al respecto, veamos la tercera acepción del término explotar: “3. Utilizar en provecho propio, por lo general de un modo abusivo, las cualidades o sentimientos de una persona, de un suceso o de una circunstancia cualquiera” (Real Academia Española, 2001: 692). Si analizamos la situación de la protagonista, ella cumple muchas de las características que la convierten en un ser explotado. Es una niña indefensa de gran talento, pero de quien es fácil abusar en beneficio de la empresa circense.

La condición de Miss Orquídea expresa la tradición del circo en relación con la muerte: "La acrobacia antigua era a menudo ligada a ritos fúnebres: el salto del acróbata, la habilidad del contorsionista que tenía como función conjurar la muerte mimando el surgimiento irreprimible de la vida” (Starobinski, 2002: 101). Riesgo de muerte que está íntimamente ligado con la ausencia del carácter de sublimación de energías que todo trabajo debiera de cumplir (León, 2002: 76), y que es desvirtuado, debido a la explotación laboral que se comete en desmedro de la integridad de la protagonista.

$\mathrm{Al}$ comprender tal riqueza expresiva en El vuelo de los cóndores, nos percatamos que también denuncia la explotación laboral infantil y la desvirtuación de la naturaleza del trabajo en su relación 
con la muerte en el contexto circense. A respecto, en vida, Valdelomar tenía la preocupación por los infantes; como intelectual, manifestó este interés tanto en sus creaciones literarias como en los discursos ofrecidos durante el ciclo de conferencias que realizó en sus viajes al interior del Perú: "El pisqueño [Valdelomar] verdaderamente ofreció una espléndida clase colmada de frases dulces y sanos consejos, elaborados y proferidos con genuino amor a la niñez. Pronunció su regia Oración a San Martín, que los escolares aplaudieron frenéticamente" (Espinoza, 2014: 97).

En cuanto a Fénix, la explotación laboral es mucho más descarnada que En el vuelo de los cóndores, debido a que asistimos a una época histórica y literaria distinta a la de Valdelomar. Ribeyro se inscribe en una escuela "neorrealista" para manifestar un mensaje crítico con respecto a la vorágine citadina, siempre en constante lucha dominante del más fuerte por sobre el más débil en un ambiente dialéctico. Debido a este dinamismo, se ha calificado a Ribeyro como: "un gran explorador de formas literarias" (Gutiérrez, 1999: 12). Verbigracia, en Fénix se aprecia una técnica literaria experimental y dinámica: el monólogo interno desde múltiples perspectivas; diferentes personajes toman la palabra para manifestar sus diversos puntos de vista, entretejiendo así la trama narrativa.

Un punto clave para comprender la explotación laboral en este circo es reflexionar sobre el pensamiento del dueño de esta empresa, que, a diferencia con El vuelo de los cóndores, recae en Marcial Chacón, quien se expresa a través de monólogos. Lo singular en su confesión es que Chacón expone su (in)moralidad sin tapujos:

Pero sobre todo, hago que trabajen los demás ... Soy superior a ellos, ¿quién me lo puede discutir? Reconozco también que hay superiores a mí: los que tienen más plata. El resto, son mis sirvientes, los compro. Soy superior al enano Max, más alto que él, más rico: le pego cuando me da la gana. Soy superior a Irma, puesto 
que la alimento y hago que se gane la vida y la meto a mi cama cuando me place. Soy superior a Fénix, porque puedo despacharlo del circo en cualquier momento $u$ ordenarle que levante pesas más pesadas. Soy superior al oso porque soy más inteligente. Soy superior a todos estos soldados porque no tengo jefe (Ribeyro, 1972: 124).

Los parámetros con los cuales Chacón mide y se siente dominante son los siguientes: físico (sobre Max), sexual (sobre Irma), de independencia laboral (con respecto a Fénix y a los soldados), racional (ante la naturaleza animal de Kong). Y, sobre todo, estos parámetros giran en torno al poder económico.

Por el nivel del habla que utiliza este empresario, nos percatamos que se trata de un "criollo". Esta categoría de comportamiento social en la realidad peruana se relaciona con la "criollada, la pendejada, la viveza”. Veamos la acepción de la locución sustantiva "viveza criolla": "Habilidad para aprovechar las circunstancias con el fin de obtener beneficios en desmedro de otros" (Academia Peruana de la Lengua, 2016: 1016). Esta práctica es la característica imperante que guía su accionar; así cuando el oso Kong no puede pelear porque está deteriorado físicamente, el empresario no desea perder dinero e idea disfrazar a Fénix con una piel de oso: "Lo peor sería que el oso se me derrumbe en plena pelea y se den cuenta de la estafa" (Ribeyro, 1972: 132). Y ya cuando se va a consumar el engaño, se dirige al público en tono patético: "Arriesgando mi vida no vacilo esta noche en salir al ruedo frente a tan furioso enemigo, solamente por el cariño que tengo a mi público y porque la divisa de mi circo es: 'Entretener, aunque reventemos"' (136).

Vía los monólogos de Chacón nos formamos un concepto acerca del pensamiento que le guía y que lo configura como un tipo de lastre humano presente en la sociedad: 
"El vivo vive del pobre y el pobre de su trabajo" ... Entiéndase como "vivos" a las alimañas o sanguijuelas que viven de su retorcida inteligencia chupando la sangre de la sociedad, sean estos profesionales o delincuentes comunes. Proliferan en la sociedad donde se enquistan medrando de la buena fe y confianza de las personas, y hasta alardean de sus "proezas", destruyendo al mismo tiempo algo precioso en la sociedad: la confianza (Morillas, 2014: 53).

A quien se engańa con la farsa de un enfrentamiento trucado es al público espectador. Esta falsificación de lucha circense es punto clave en la narración pues se constituye en símbolo social y estético, ya que plantea las categorías de alienación y desalienación que se presentan en constante pugna en el ámbito del trabajo. En este cuento, gana la desalienación vía el accionar de Fénix. Entendemos esta categoría como el salto cualitativo que recala en la iluminación de naturaleza juiciosa que guía al hombre en su integridad individual y social como: "el control consciente, libre en el caso de que atańa a un solo individuo, y democrático, en el caso de que atańa a una colectividad (es decir, autogestionado en todos los casos), de los procesos de subjetivación, praxis y objetivación de la realidad que realizan los sujetos en sus vínculos" (León, 2002: 144).

En el acuerdo laboral de la farsa de lucha, el patrón, de conducta "criolla", no cumple con lo pactado, lo que sorprende a Fénix: "Pero ¿cuándo terminaremos? Tiene que hacerme la seña ... ¡Otra vez el puñete! Y se va para atrás. Eso no me lo había dicho, que me iba a dar fuerte en la cabeza" (Ribeyro, 1972: 138). Chacón se aprovecha de la ocasión para maltratar a Fénix. No obstante, el accionar del fortachón, cansado de tanto abuso, mudará en acto rebelde en contra de la alienación a la cual ha sido sometido en trabajo explotador, inhumano: "Harto ya, harto Chacón, harto de tanto calor, de tanto contrazuelazo. Déjame echarme sobre ti un rato, sólo un ratito" (140). 
Debido a que asistimos a un texto literario, este acto de desalienación tiene una significativa carga estética. Reflexionemos en la semántica del nombre circense del fortachón, Fénix, y en la mudanza en disfraz de piel de oso; ambos tópicos connotan cambio, rebeldía ante la alienación establecida por la explotación laboral del circo como también un renacer esperanzador hacia una nueva consciencia individual y colectiva. Fénix aplastará a Chacón ante el sobresalto del público espectador: “¿No oyes cómo grita la gente? Diles que hacemos circo, circo para que se entretengan. Circo hago desde que nací. Haz circo tú también” (Ribeyro, 1972: 140).

Aquí se configura la presencia de una imagen simbólica y compleja que debido a presentarse en el circo es de semántica problemática, en vaivén entre la realidad y lo ficticio: "La imagen ofrece, al contrario, la ilusión de crear un contexto, de reflejar la realidad en el conjunto de sus dimensiones mientras procede por abstracción de un fragmento de realidad. Este poder de la imagen es problemático cuando pretende transcribir fielmente lo real. El circo se inscribe en otra lógica. Las imágenes que nos deja ver son siempre ficción” (Bailly, 2009: 74).

Ahora bien, tratemos de interpretar esta imagen circense del cambio de rol y disfraz, y su relación con la desalienación por parte de Fénix. Este accionar se constituye en cambio cualitativo de iluminación en camino de libertad, desafiante al statu quo representado por el poder militar, que no distingue entre el disfraz y el humano que está camuflado en él, pues en el circo, como se mencionó anteriormente, las imágenes que se ven son siempre ficción. Fénix al escapar de esa fuerza de dominio, dice: "Avanzo hacia el agua, sereno al fin, a hundirme en ella, a cruzar la selva, tal vez a construir una ciudad ... yo mismo soy una fuerza y avanzo aunque no haya camino. Me hago un camino avanzando" (Ribeyro, 1972: 142). Nótese un renacer, una iluminación de liberación. Nuevos bríos en su accionar y su discurso, pues Fénix ha vuelto a encontrarse a 
sí mismo en un renacer de ave fénix, en este caso al humanizarse en un proceso de desalienación que se despoja de las condiciones alienantes del trabajo.

A propósito, recordamos que este cuento forma parte de Tres historias sublevantes, cuento dedicado al poeta Javier Heraud; destellos sutiles que proporcionan claves para entender la esencia de esta narración. Javier Heraud fue un joven poeta que marcó a su generación con su gesto revolucionario en la selva peruana:

En 1963 formó parte del Ejército de Liberación Nacional (ELN), con la misión de abrir un frente guerrillero en la zona de Puerto Maldonado. Las difíciles condiciones del viaje por río y la falta de conocimiento de la zona afectaron fuertemente al grupo guerrillero. Algunos de sus integrantes incluso contrajeron uta. El 15 de mayo de 1963, durante un arriesgado intento por llegar a Puerto Maldonado para obtener atención médica, Heraud murió acribillado por la policía nacional (Contreras y Cueto, 2016: 43).

No obstante, debemos entender que Ribeyro no militó en partido político alguno, aunque su obra revela identificación con los desamparados, una compasión por los que no son escuchados. Mediante su obra, él les otorga voz al denunciar la opresión de sus derechos. Coherente con esta postura, tuvo afinidad política con el pensamiento de izquierda como él mismo lo confesó: "No soy de izquierda, aunque he tenido actitudes y acciones izquierdistas. Por ejemplo, apoyé a la guerrilla del 64, de Javier Heraud, o a la guerrilla del 65, de Guillermo Lobatón, Paul Escobar y otros” (Coaguila, 2018: 7).

Para concluir con el análisis de esta sección, reflexionemos sobre lo hasta ahora analizado. En esencia, en ambos cuentos existe la figura de la explotación laboral circense, sin embargo, en Fénix, la presencia objetiva del explotador y los métodos que utiliza para 
alcanzar sus fines son mucho más descarnados que en El vuelo de los cóndores, puesto que este personaje pertenece al tipo social del "criollo" muy presente en la sociedad peruana. En Fénix, la desalienación como accionar humano de rebeldía y libertad se configura en significativa carga simbólica. Fénix al superar la explotación laboral circense, en cambio cualitativo, se forja un nuevo destino: "El poder nuevamente se representa en la mano de un abusador, y, es precisamente por eso, que el cuento alcanza el mismo tópico de lucha del hombre por alcanzar su propia justicia” (Sánchez, 2017: 61).

En El vuelo de los cóndores, Valdelomar representa la explotación laboral circense no directamente planificada, sino mediante el azar del accidente que sufre Miss Orquídea. Se deduce la opresión por parte de la administración del circo, ya que el trabajo que desempeña esta niña no cumple con la condición de sublimación de energías, esto es, la realización del ser humano como ser íntegro y más aún, en el circo, se atenta contra su integridad humana en un espectáculo en donde el riesgo de muerte está siempre presente. Esta condición de explotación laboral se consolida debido a que ella es infante y de género femenino, estados que la vuelven muy vulnerable.

Creemos que estos tópicos de explotación laboral en el circo critican al sistema laboral y económico imperante. Tanto a lo inhumano y desvirtuado en que este puede tornarse, como al giro esperanzador de rebeldía y liberación que en salto cualitativo de desalienación puede conectar al hombre en su verdadera esencia humana.

\section{Principales personajes que integran el circo}

En un estudio que analiza la temática circense en la obra de Gómez de la Serna, se seńala como personajes de circo a los números que integran los actos de gimnasia y contorsión, a los animales 
exóticos como elefantes, leones o focas y a los simuladores de lo sobrenatural, a los ilusionistas, prestidigitadores y magos (Rivas, 202: 516). Al distinguir a estos actantes circenses, nos percatamos que existen en los dos cuentos analizados. No obstante, en El vuelo de los cóndores, estos son solo descritos desde la perspectiva del niño Abraham, lo cual nos limita a profundizar en sus circunstancias; el único personaje en el que se puede ahondar es en Miss Orquídea; en cuanto a Fénix, por su estructura en monólogos, nos enteramos a detalle sobre la suerte de Irma, del Enano Max y de Kong.

Por tanto, en primer lugar, analizaremos a Miss Orquídea y a Irma. Las dos son personajes femeninos que trabajan con sus cuerpos, una, equilibrista, la otra, contorsionista. Entendiendo este vínculo de género y función laboral, busquemos otros: ambas son explotadas laboralmente y se ven implicadas en sentimiento amoroso. El amor forma parte de la vida: "la vida que [en el circo] se está evocando de manera irresistible, en sus aspectos más triviales y en sus impulsos más sublimes" (Bailly, 2009: 66).

En El vuelo de los cóndores el amor es inocente, ya que el foco sentimental emana del niño Abraham, quien sueña cándidamente con la trapecista. La correspondencia a este amor se manifiesta de forma sutil en la amistad silenciosa que ambos cultivan durante ocho días en el paseo diario de Abraham rumbo al colegio. Aquí es simbólico el estatismo de ella. Como se mencionó antes, el trabajo de Miss Orquídea no cumple con la condición de sublimación en realización integral, y se ve desvirtuado en el accidente.

Ella trabaja mediante su físico. Ahora, partamos de la siguiente idea: "El circo ilustra no solo las capacidades del cuerpo, sino también la potencia de un cuerpo perfectamente disciplinado. No obstante, la imagen del cuerpo circense es más ambigua. Es más que el icono de un ideal de sumisión a la conminación disciplinaria. Representa todo lo que se escapa de él y que resiste a la subordinación” (Bailly, 2009: 77). Después del accidente de trabajo, la 
niña se queda tullida, estática. Si entendemos que el concepto de desalienación es de carácter activo, en donde el sujeto alcanza una consciencia de liberación y busca los medios de actuación para integrarse con su esencia humana, tanto individual como colectiva, aquí el cuerpo de ella se ve impedido de actuación y rebeldía y, por tanto, no se consolidan los actos de liberación. Más aún, esta misma actitud es transferida en el personaje con el que se relaciona emocionalmente, el niño Abraham. Y no hay que extrańarnos, porque ambos protagonistas son infantiles física y emocionalmente. Ellos todavía no han adquirido una madurez que los ilumine hacia una consciencia de clase que guíe su accionar.

En cambio, en Fénix el amor de Irma es incendiario. Ella, desde sus monólogos confiesa un sentimiento plagado de deseo anhelante de protección, pero a la vez resignado: "Si yo lo hubiera conocido en ese tiempo lo querría, lo querría como una loca, y me hubiera hundido para siempre en su pecho, me hubiera convertido en un pelo suyo, en una cicatriz, en un tatuaje. Pero Fénix llegó a mí cansado" (Ribeyro, 1972: 123). Nótese que Irma es realista, sabe muy bien que el amor entre los dos es imposible. Más adelante ella le coserá la cabeza del disfraz de oso y comprenderá que entre ambos hay una distancia insalvable: "yo mujer y él sólo [sic] una bestia” (Ribeyro, 1972: 135).

Sabemos que Fénix no está considerado dentro de los más resaltantes cuentos de Ribeyro, sin embargo, en su experimentación literaria se presentan momentos sutiles:

y de ahí que sus textos más débiles -por ejemplo, "Fénix", "Los predicadores" o "Las cosas andan mal, Carmelo Rosa"- son aquellos en que ha abandonado su tono habitual del lenguaje, por otro supuestamente más moderno e innovador; sin embargo es preciso destacar que aún en sus relatos menos memorables siempre se encuentra una frase, un matiz, una impresión o reflexión que revela 
la huella, la marca, la calidad inconfundible de Ribeyro (Gutiérrez, 1999: 12).

Creemos que la sutileza de este cuento radica en el amor que Irma profesa a Fénix. A diferencia de El vuelo de los cóndores, los involucrados son dos personas adultas que viven en constante explotación laboral. Ella es violada y sufre maltrato físico de forma sistemática; Fénix, por su lado, con su accionar de desalienación, se libera y la libera a ella al matar a Chacón. No es un ente estático, como Miss Orquídea o Abraham, sino que decide cambiar su destino, el del ser amado y demás compañeros de trabajo. Para aligerar la seriedad de este acto en sí, Ribeyro inserta un detalle cómico, propio del circo grotesco, en el accionar del Enano Max vía la perspectiva de Irma: "El enano pasa al lado de Fénix y va donde Marcial, se agacha, le mira la cara, le mete un dedo en el ojo, lo jala de la lengua, se desabrocha la bragueta, se pone a mear" (Ribeyro, 1972: 141).

De manera equivocada y parcializada se ha encasillado a Ribeyro como desesperanzador al presentarnos la ruina humana y social. Ribeyro, como el gran autor que es, tiene una obra compleja, la cual debiera analizarse en sus diferentes aristas. No siempre el autor es escéptico en torno al potencial humano. Veamos, en Los geniecillos dominicales, la juventud es caracterizada por un sentido de frustración:

es la juventud el momento en que se descubre, a veces muy oscuramente, que el vivir concreto del hombre está señalado por alguna forma de inautenticidad e inmerso en un mundo malhecho, deforme y arbitrario, que irremisiblemente condena al sujeto a traicionar lo mejor de sí mismo. La novela de Ribeyro se inscribe de lleno en esta línea (Cornejo, 1977: 157). 
No obstante, en Fénix, los personajes de Irma y Fénix no traicionan a lo mejor de sí. Es su accionar de desalienación, una luz de esperanza humana. Recordemos que esta es la línea temática en la que se inscribe Tres historias sublevantes:

Acá el escritor ha ampliado su perspectiva. No todos - parece decirnos- aceptan la fatalidad de la miseria y su menoscabo. Y para ilustrarlo están estas tres fábulas de la lucha de los desdichados contra la desdicha que no es un "fatum" supremo e inapelable sino un reversible estado de cosas cuyo pivote es la injusticia (Salazar, 1964: 8).

Continuando, en cuanto a la suerte de los animales circenses, en El vuelo de los cóndores no existe maltrato animal, puesto que como veremos más adelante- el circo no es decadente. En cambio, en Fénix, la suerte del oso Kong es alarmante; mala alimentación, vejez y desempeño en un hábitat no adecuado a su naturaleza son las causas principales de su mal estado de salud: "Lo que le falta a Kong es comida ... carne de perro callejero, de mulo que se muere en los potreros. Aquí solo yerbas y raíces. Además, está viejo el pobre Kong, que ni dientes tiene. Este calor le hace daño también, ya se desacostumbró con tanto tiempo que ha pasado en otros climas" (Ribeyro, 1972: 131). El maltrato animal se incrementa cuando Fénix al tratar de reanimar a Kong, inútilmente sacrifica a un monito. Aquí se aprecia la suerte del enano Max que ambiciona la piel del animalito como abrigo, ya que se infiere que no gana lo suficiente para poder vestirse decentemente. Humanos y animales unidos en el infortunio y desamparo.

Hasta aquí, nos percatamos que los personajes circenses, tanto humanos como animales, corren suertes distintas en los dos cuentos. En El vuelo de los cóndores, Miss Orquídea por su condición de estatismo corporal, debido al accidente que sufre en el trabajo 
circense, no actúa en búsqueda de un cambio que la libere de la alienación laboral que padece. Esta condición también es transferida en el niño Abraham, con quien comparte un vínculo emocional de amor infantil. En cambio, en Fénix el amor maduro inspira al acto dinámico de rebeldía y desalienación por parte del accionar esperanzador configurado en el acto de emancipación llevado a cabo por Fénix al matar a Chacón y así, liberarse y liberar a Irma y a sus compañeros del trabajo alienante del circo.

En cuanto a la suerte de los animales circenses, en El vuelo de los cóndores no se manifiesta maltrato alguno hacia ellos. Caso contrario sucede en Fénix, donde el oso Kong se expone a malas condiciones de alimentación, vejez e inadecuado cambio de hábitat. Estas circunstancias se vinculan con el valor social que adquiere el circo, aspecto que será analizado en la siguiente sección de esta investigación.

\section{Valor social del circo}

El circo cumple diferentes funciones en la sociedad. La del entretenimiento es la que sobresale. El espectador debe de ingresar al espectáculo con cierta inocencia para que pueda disfrutarlo plenamente en solaz y fantasía: "Al circo van los niños y los hombres-niños a vivir con más intensidad, a estar parados, casi, porque las sillas del circo también son acróbatas: siempre están haciendo equilibrio en una pata” (Núñez, 1928: 59).

En El vuelo de los cóndores, el niño Abraham cae presa del deslumbramiento desde su primer contacto con el circo cuando presencia obcecado el arribo de los artistas y por ello retorna tarde a casa (Valdelomar, 2014: 140). Impresión que es compartida por todo el pueblo, ya que el circo es fiesta. El cuento nos transmite un aura delicada de descripción ceremonial de espectáculo; en el desfile de "el convite", la parafernalia que envuelve a los artistas es 
galante: "Vino a pasar la banda de músicos con sus bronces ensortijados y sonoros ... en un caballo blanco, la artista Miss Blutner, con su ceñido talle, sus rosadas piernas, sus brazos desnudos y redondos. Precioso atavío llevaba el caballo, que un hombre con casaca roja y un penacho en la cabeza, lleno de cordones portaba de la brida” (Valdelomar, 2014: 143).

Galantería que también caracteriza a las tarjetas de invitación al circo en donde se consigna la programación (Valdelomar, 2014: 143). Y es que el circo que inspiró al autor fue famoso en su tiempo. Aquí un extracto de la carta que dirige Valdelomar a su madre, desde Italia, cuando confeccionaba su memorable cuento: "dime si recuerdan ustedes que un circo Nelson y Vidal que hubo en Pisco, no tenía una chiquilla que trabajaba en el circo y que se cayó una noche haciendo una prueba y casi se mata o se mató" (Ángeles, 2007: 84). Se sabe que este fue un circo británico que en su gira llegó al Perú: "Se trata, probablemente, del Circo Nelson, después rebautizado como Circo Británico Nelson, que recorrió Sudamérica en barco y carreta entre 1872 y 1894" (Mondragón, 2018: 5).

Esta atmósfera galante circense es de estética postmodernista, ya que se presenta la descripción de un ambiente costumbrista. Nótese el énfasis en la descripción de detalles culinarios criollos y jaraneros, como antesala a la función circense:

en floreados vasos con las armas de la patria estaba la espumosa blanca chicha de maní, la amarilla de garbanzos y la dulce de bonito, las butifarras, que eran panes en cuya boca abierta el ají y la lechuga ocultaban la carne; los platos con cebollas picadas en vinagre, la fuente de escabeche con sus yacentes pescados, la causa, sobre cuya blanda masa reposaba graciosamente el rojo de los camarones, el morado de las aceitunas, los pedazos de queso, los repollos verdes y el pisco oloroso, elaborado por las vendedoras (Valdelomar, 2014: 145). 
El circo valdelomariano, con todos sus matices, cumple una función social de entretenimiento familiar que en su estética postmodernista impresiona al lector con respecto a su galantería localista, la cual repercute en la vida de la clase media provinciana peruana de a comienzos del siglo xx: "Al llevar a la literatura narrativa sus pequeñas tragedias de niño provinciano, Valdelomar refleja por extensión la vida de la clase media en los poblados de la costa” (Castro, 1967: 176).

Entonces, entendiendo este nexo entre las características que muestra la institución social del circo en la ficción literaria con respecto a las costumbres y condiciones socioeconómicas de una determina época se reafirma lo siguiente: "La segmentación de públicos del circo sugiere, sin embargo, que no ha desaparecido, pero que se ha desplazado, debido a que la asistencia a ciertos tipos de espectáculos de circo puede operar como marcador de distinción" (Bailly, 2009: 65). Esta diferencia de clases sociales en su estratificación se comprenderá por contraste al analizar Fénix.

En el cuento de Ribeyro también se advierte la función de entretenimiento, sin embargo, el público no es familiar. El grueso espectador se constituye por una clase militar de baja estofa, soldados levados a la fuerza. Así también, su máxima autoridad, el teniente Sordi, ha sido castigado, por indisciplinado, a hundirse en la selva peruana, en Corral Quemado, dirigiendo a "cholos" sin vocación (Ribeyro, 1972: 126). Y debido a que bajo estas condiciones no hay mucho que producir, los soldados se regocijarán de manera burda en el espectáculo decadente de circo marginal. El cuento abunda en datos que suman esta impresión. Veamos: 1) el teniente Sordi asiste borracho al espectáculo (Ribeyro, 1972: 130); 2) el teniente Sordi sueña con seguir tomando cerveza (133); 3) el teniente Sordi, el soldado Eusebio y, por ende, la tropa completa fantasean sexualmente con Irma (133); 4) el teniente Sordi y el soldado Eusebio apuestan una libra, por quién ganará la pelea 
entre Marcial Chacón y el oso Kong, quien no es más que Fénix disfrazado (134); 5) Chacón acepta que su circo no es tan productivo (124); 6) el enano Max manifiesta el maltrato físico al que es sometido por su colega de nombre artístico Zanahoria (133); 7) los soldados hacen gestos obscenos a Irma (133); 8) el circo tiene huecos en el techo y se filtra la lluvia además de los maltratos que sufre Kong (136).

Todos estos datos nos permiten afirmar que el circo en Fénix entretiene de una forma grotesca, pues es un circo marginal. Explotación, funciones mediocres, maltrato y exposición a la procacidad sexual son sus estrategias para atraer al público. Es un circo de medio pelo que se desmoronará con la muerte de su artífice, con el acto de emancipación fraguado por Fénix. Según Bajtín (2003) estas formas grotescas del espectáculo remiten a una concepción dinámica del mundo, a la metamorfosis, a los cambios en la cultura popular y su dialéctica subversiva (Bailly, 2009: 72). Aunque sea un circo grotesco de espectáculo marginal, en su esencia no deja de presentarnos una dialéctica de subversión. En la dicotomía de construir situaciones burdas como medio para transmitir la denuncia social, tan sutil y humana en su esencia, con respecto al fenómeno de la desalienación del individuo, radica el valor de este cuento.

Es por ello que entendemos que Ribeyro, aunque de guiño esperanzador cuando trabaja con los temas de sublevación y desalienación laboral, sigue practicando un neorrealismo grotesco de denuncia social urbana. Él siempre fue categórico en cuanto a su concepción del estilo como voz propia, profunda y original del autor: "No hay que buscar la palabra más justa, ni la palabra más bella, ni la palabra más rara -dice Luder-. Busca solamente tu propia palabra” (Ribeyro, 2018: 66). Así el estilo neorrealista que practicó desde sus comienzos como escritor urbanista en la Lima de a mediados del siglo xx sigue vigente en Fénix. A propósito, 
una valoración hacia la literatura del joven Ribeyro: "Alterna allí [en el cuento corto] la imagen grotesca y revulsiva de la barriada marginal, los recuerdos autobiográficos nimbados de melancólica poesía, la sátira alegorizante, la nostalgia por el esfumado reino de la infancia (Castro, 1967: 260).

En síntesis, el valor social del circo en ambos cuentos se relaciona con la función del entretenimiento. En cuanto al circo valdelomariano de estilo postmodernista, se ve rodeado de una atmósfera galante de espectáculo familiar que refleja las costumbres de la clase media provinciana peruana de a inicios del siglo xx. En cambio, en Fénix asistimos a un circo marginal de mediados del mismo siglo, cuento que, en lo grotesco de su estética neorrealista, denuncia de manera esperanzadora la desalienación laboral del hombre en dialéctica de sublevación y liberación en búsqueda de la realización.

\section{Conclusiones}

Se han analizado los cuentos El vuelo de los cóndores y Fénix desde una metodología de crítica sociológica aplicada a la literatura y se ha tomado en cuenta tres aspectos en concreto. En primer lugar, ambos cuentos desarrollan tópicos de explotación laboral en el circo que critican al sistema económico imperante. Tanto a lo inhumano y desvirtuado en que este puede tornarse, como al giro esperanzador de rebeldía y liberación que en salto cualitativo de desalienación puede conectar al hombre en su verdadera esencia humana. En segundo lugar, en lo concerniente a los personajes que integran el circo, los seres humanos muestran un estatismo en su actuar, que se relaciona con la alienación laboral, y un dinamismo libertador, que se vincula con la desalienación. Además, la suerte de los animales del circo guarda relación con el valor social que este adquiere, el cual, según el tercer aspecto de este análisis, tiene como función principal al entretenimiento, tanto desde una 
estética literaria inscrita en el postmodernismo, con una galantería localista, como con el neorrealismo, que en su estética grotesca denuncia de manera esperanzadora la lucha del hombre por alcanzar su libertad.

Aquí solo cabe resaltar, que cada cuento en su singularidad nos presenta la alegoría del circo como reflejo de la complejidad humana y social en sus alegrías, injusticias y vicisitudes; razón por la cual a sus artífices se les puede considerar como los dos cuentistas más importantes de la literatura peruana.

\section{Bibliografía}

Ángeles Caballero, César Augusto, 2007, Epistolario de Abraham Valdelomar, Universidad Alas Peruanas, Lima.

Bailly, Brigitte, 2009, “El circo: ¿mezcla de géneros?”, Folios, núm. 29, pp. 63-81. Disponible en: https://revistas.pedagogica.edu. co/index.php/RF/article/view/6127 (Consultado: 18/XI/2019).

Bajtín, Mijaíl, 2003, L'ouvre de François Rabelais et la culture populaire au Moyen-Âge et sous la Renaissance, Gallimard, París.

Castro Arenas, Mario, 1967, La novela peruana y la evolución social, José Godard Editores, Lima.

Coaguila, Jorge, 2018, Ribeyro, la palabra inmortal, Revuelta Editores, Lima.

Contreras, Carlos y Marcos Cueto, 2016, Crisis y reforma. Restauración oligárquica y nuevos actores (1948-1968), vol. 8, Septiembre, Colección Historia del Perú Republicano, Lima.

Cornejo Polar, Antonio, 1977, "Los geniecillos dominicales: sus fortunas y adversidades", en La novela peruana: siete estudios, Horizonte, Lima, pp. 145-158. 
Diccionario de peruanismos DiPerú, 2016, Academia Peruana de la Lengua, Lima.

Espinoza Soriano, Waldemar, 2014, Valdelomar en Cajamarca, Universidad Ricardo Palma, Lima.

Garayar, Carlos, 2014, "Lima y el Palais Concert. Notas sobre el autor y su tiempo", en Abraham Valdelomar, Cuentos reunidos, Peisa, Lima, pp. 21-25.

Gutiérrez Correa, Miguel, 1999, "El cuentista”, en Ribeyro en dos ensayos, San Marcos, Lima, pp. 12-81.

León Medina, Francisco José, 2002, Alienación y sufrimiento en el trabajo. Una aproximación desde el marxismo, tesis doctoral, Universitat Autònoma de Barcelona, Barcelona.

Lukács, Gyorgy, 1989, Sociología de la Literatura, Ediciones Península, Barcelona.

Mariátegui, José Carlos, 2010, 7 ensayos de interpretación de la realidad peruana, Editora El Comercio, Lima.

Mondragón, Rafael, 2018, "La elocuencia silenciosa de los gestos. El circo en Mariátegui", Conjunto. Revista de teatro latinoamericano, núm. 189, pp. 1-11.

Morillas, Pedro, 2014, Pais combi, Summa, Lima.

Núñez, Estuardo, 1928, "Meditación del circo", Amauta, núm. 17, pp. 58-59.

Real Academia Española, 2001, Diccionario de la lengua española, vol. 5, Espasa, Madrid, pp. 619-784.

Ribeyro, Julio Ramón, 2018, Dichos de Luder presentados por Julio Ramón Ribeyro, Revuelta Editores, Lima. , 1972, "Fénix", en La palabra del mudo, Milla Batres, Lima, pp. 123-142.

Rivas Bonillo, Antonio, 2012, "Literatura y espectáculo: El circo (1917), de Ramón Gómez de La Serna”, en Actas del XVIII 
Simposio de la SELGYC, Biblioteca Virtual Miguel de Cervantes, pp. 509-519. Disponible en: http://www.cervantesvirtual. com/obra/xviii-simposio-de-la-selgyc-alicante-9-11-de-septiembre-2010--xviii-simposi-de-la-selgyc-alacant-9-11-setembre-de-2010/ (Consultado: 8/V/2019).

Salazar Bondy, Sebastián, 1964, "Ribeyro, nueva perspectiva. Nota sobre Tres historias sublevantes", Suplemento Dominical de El Comercio, p. 8. Disponible en: http://www.casadelaliteratura.gob.pe/ribeyro-nueva-perspectiva-por-sebastian-salazarbondy/ (Consultado: 8/V/2019).

Sánchez Valera, Ana María, 2017, Ficción realista y transformación social del hombre en los cuentos de Tres historias sublevantes de Julio Ramón Ribeyro, tesis de licenciatura, Universidad Nacional del Altiplano, Puno.

Starobinski, Jean, 2004, Portrait de l'artiste en saltimbanque, Gallimard, París.

Tenorio Resquejo, Néstor, 2002, "Para leer a J.R. Ribeyro", UMBRAL. Revista de Educación, Cultura y Sociedad, núm. 3, pp. 122-131.

Valdelomar, Abraham, 2014, "El vuelo de los cóndores”, en Cuentos reunidos, Peisa, Lima, pp. 139-149.

Vásquez Peńa, José, 2000, “El Hipocampo de Oro: Umbral de la narrativa infanto- juvenil peruana”, en Valdelomar para niños y jóvenes, San Marcos, Lima, pp. 133-141. 